Trinity University

Digital Commons @ Trinity

Biology Faculty Research

Biology Department

$3-2018$

\title{
Ecomorphological Variation in Three Species of Cybotoid Anoles
}

A. F. Kahrl

Brittney M. Ivanov

Trinity University, bivanov@trinity.edu

K. C. Wollenberg Valero

Michele A. Johnson

Trinity University, mjohnso9@trinity.edu

Follow this and additional works at: https://digitalcommons.trinity.edu/bio_faculty

Part of the Biology Commons

\section{Repository Citation}

Kahrl, A.F., Ivanov, B.M., Wollenberg Valero, K.C., \& Johnson, M.A. (2018). Ecomorphological variation in three species of cubotoid anoles. Herpetologica, 74(1), 29-37. doi:10.1655/Herpetologica-D-17-00040

This Article is brought to you for free and open access by the Biology Department at Digital Commons @ Trinity. It has been accepted for inclusion in Biology Faculty Research by an authorized administrator of Digital Commons @ Trinity. For more information, please contact jcostanz@trinity.edu. 


\section{Ecomorphological Variation in Three Species of Cybotoid Anoles}

Author(s): Ariel F. Kahrl, Brittney M. Ivanov, Katharina C. Wollenberg Valero, and Michele A. Johnson Source: Herpetologica, 74(1):29-37.

Published By: The Herpetologists' League

https://doi.org/10.1655/Herpetologica-D-17-00040

URL: http://www.bioone.org/doi/full/10.1655/Herpetologica-D-17-00040

BioOne (www.bioone.org) is a nonprofit, online aggregation of core research in the biological, ecological, and environmental sciences. BioOne provides a sustainable online platform for over 170 journals and books published by nonprofit societies, associations, museums, institutions, and presses.

Your use of this PDF, the BioOne Web site, and all posted and associated content indicates your acceptance of BioOne's Terms of Use, available at www.bioone.org/page/terms_of_use.

Usage of BioOne content is strictly limited to personal, educational, and non-commercial use. Commercial inquiries or rights and permissions requests should be directed to the individual publisher as copyright holder. 


\title{
Ecomorphological Variation in Three Species of Cybotoid Anoles
}

\author{
Ariel F. Kahrl ${ }^{1}$, Brittney M. Ivanov ${ }^{2}$, Katharina C. Wollenberg Valero ${ }^{3}$, and Michele A. Johnson ${ }^{2,4}$ \\ ${ }^{1}$ Zoologiska Institutionen: Etologi, Stockholm University, Stockholm, SE-10691, Sweden \\ 2 Department of Biology, Trinity University, San Antonio, TX 78212, USA \\ ${ }^{3}$ School of Environmental Sciences, University of Hull, Hull, HU6 7RX, United Kingdom
}

\begin{abstract}
AвstRAct: Caribbean Anolis lizards exhibit a complex suite of ecological, morphological, and behavioral traits that allow their specialization to particular microhabitats. These microhabitat specialists, called ecomorphs, have independently evolved on the four islands of the Greater Antilles, and diversification among anole ecomorphs has been the focus of many studies. Yet, habitat specialization has also occurred among species within the same ecomorph group. Here, we examined ecological, morphological, and behavioral divergence in three Hispaniolan trunk-ground species, the cybotoid anoles: Anolis cybotes, A. marcanoi, and A. longitibialis. We found differences in limb morphology, locomotor behavior, and perch use among the three cybotoid species that mirror differences across the ecomorphs. Among these species of cybotoids, those that have longer limbs tend to move less frequently, occupy broader perches, and have smaller fourth toes with fewer lamellae. We also observed that the species with greater male-biased size dimorphism had larger heads, smaller dewlaps, and smaller testes. These results are consistent with the predictions of sexual selection theory, in that species with large male body size may have larger heads because of increased male-male combat, and smaller testes potentially attributable to a trade-off between pre- and postcopulatory selection. Overall, our study suggests that a combination of local adaptation to different structural habitats and sexual selection might produce ecomorphological diversification within cybotoid anoles of the same ecomorph group.
\end{abstract}

Key words: Anolis; Dewlap; Hindlimb; Locomotor behavior; Perch use; Sexual size dimorphism

ECOMORPHOLOGY, the study of the relationship between an organism's ecology and its morphology, has revealed that evolution often shapes complex suites of traits to allow specialization to a particular environment. The evolution of such phenotypic suites has facilitated divergence into diverse habitats, driving adaptive radiations in multiple taxa (reviewed in Schluter 2000). In some groups, ecomorphological evolution has produced strikingly repeatable results, resulting in discrete classes of species adapted to a set of niches (e.g., Eleutherodactylus frogs, Hedges 1989; Anolis lizards, Losos et al. 1998; cichlid fish, Danley and Kocher 2001; boas and pythons, Esquerré and Keogh 2016). When habitat specialization in multiple, independent lineages results in the convergent evolution of ecology, morphology, and behavior, the resulting classes are termed "ecomorphs" (following Williams 1972), defined as specialists to a particular microhabitat. Although the evolution of ecomorphs has been a focus of many studies (e.g., Schluter 2000), divergence within an ecomorph, which can result in further habitat specialization (Losos 1996), has received far less attention.

Of the approximately 150 species of anole lizards (genus Anolis) in the Caribbean, most are categorized as one of six ecomorphs: trunk-ground, trunk-crown, trunk, grass-bush, twig, and crown giant (Williams 1972, 1983; Losos 2009). Specific ecomorphs have independently evolved on each of the islands of the Greater Antilles (Losos et al. 1998), and species within an ecomorph exhibit coordinated combinations of adaptations to their structural microhabitat. For example, trunk-ground species are generally medium-sized (male snout-vent length [SVL] from 50 to $75 \mathrm{~mm}$ ), brown lizards with long limbs and a stocky build. As sit-and-wait predators, they perch low on tree trunks and forage on the ground and in low vegetation. On the other hand, twig species are mottled gray or brown, have short limbs and

\footnotetext{
${ }^{4}$ Correspondence: e-mail, mjohnso9@trinity.edu
}

narrow bodies, and move slowly and cryptically on small branches in the canopy. There is a rich body of literature that compares a wide range of traits both among and within the anole ecomorphs (reviewed in Losos 2009; Wollenberg et al. 2013; Kamath and Losos 2017), but the majority of studies about within-ecomorph variation has focused on variation in traits not directly associated with anole ecomorphology (e.g., thermal ecology, Ruibal 1961; Rand 1964; Hertz et al. 2013; body size, Muñoz et al. 2014). In this study, we examined variation in the morphological, ecological, and behavioral traits that distinguish different ecomorphs within several species of a single ecomorph: the Hispaniolan trunk-ground anoles.

These closely related anoles, termed the "cybotoids," have spread into different macrohabitats across the Dominican Republic and Haiti. Thus, this clade offers an ideal opportunity to examine patterns of diversification within an ecomorph (Glor et al. 2003; Wollenberg et al. 2013). The group of cybotoid lizards includes A. cybotes (including A. armouri and A. shrevei, which are phylogenetically nested within the A. cybotes group; Wollenberg et al. 2013), A. marcanoi, A. whitemani, A. longitibialis, and A. strahmi. Here, we focus on three of these species (Fig. 1): A. cybotes, a macrohabitat generalist that occurs throughout the island of Hispaniola, generally at elevations below $1800 \mathrm{~m}$; A. longitibialis, a species restricted to rocky outcrops in the xeric southwestern Dominican Republic (Gifford et al. 2003); and A. marcanoi, a species that occurs in southcentral Dominican Republic in semixeric to semimesic forest habitats (Glor et al. 2003). Using these three species, we tested for differences in ecological, behavioral, and morphological traits among species of cybotoid anoles, and compared these patterns with the known patterns of among-ecomorph diversification.

One of the defining traits of anole ecomorphs is based on the relationship between limb morphology and perch 


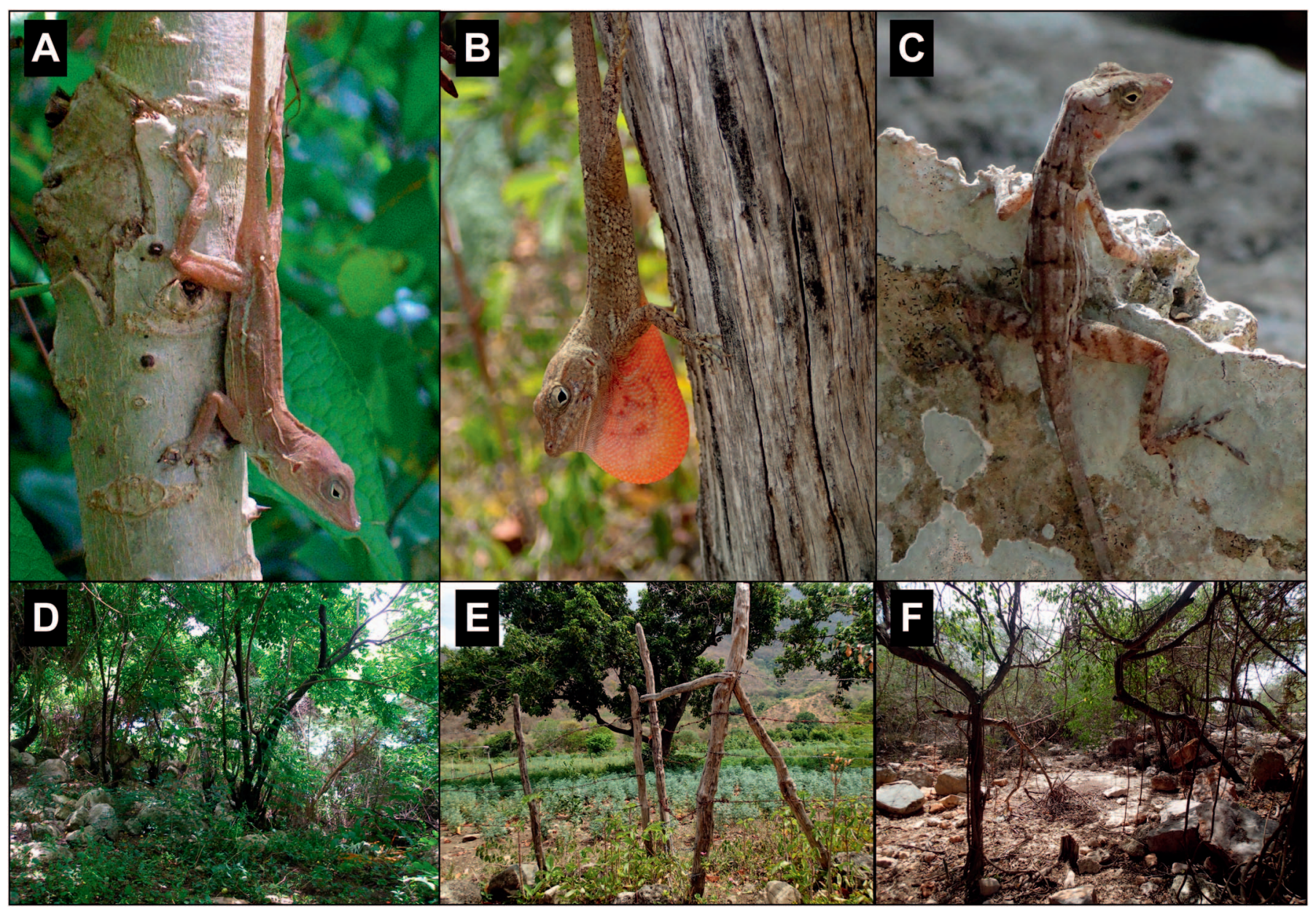

Fig. 1.-Photographs of adult male Anolis cybotes (A), A. marcanoi (B), and A. longitibialis (C), and their respective representative habitats: La Ciénaga, Barahona (D), the road to El Matedero north of Bani (E), and Manuel Goya (F) in the Dominican Republic. A color version of this figure is available online.

diameter. Longer-limbed species (i.e., trunk-ground and trunk-crown species) predominantly use larger or broader perches and exhibit greater sprint speeds on broad perches than shorter-limbed species (i.e., grass-bush and twig species; Losos 1990; Irschick and Losos 1999), whereas shorter limbs are generally associated with increased maneuverability on smaller perches (Losos and Sinervo 1989; Irschick and Losos 1998). In addition, toepad morphology is associated with clinging ability in anoles (Irschick et al. 1996), and the more arboreal anole ecomorphs generally have larger subdigital toepads, with more adhesive lamellae, than the more terrestrial ecomorphs (Glossip and Losos 1997). Locomotor performance in anoles is also dependent on substrate type (smooth or rough) and angle of incline, with lizards running faster on rough substrates and larger males pausing or slipping more frequently on smooth, vertical substrates (Kolbe et al. 2015). Furthermore, anoles preferentially use perches that allow maximum locomotor performance (Irschick and Losos 1999; but see Kolbe et al. 2015). Based on these findings, we tested three predictions regarding limb morphology, perch use, and locomotor behavior: (1a) Species with longer limbs, larger toepads, and more lamellae on their toepads will use broader perches. (1b) Longer-limbed species will perform more fast locomotor movements (i.e., runs and jumps), and shorter-limbed species will perform more slow movements (i.e., crawls). (1c) The macrohabitat generalist species (A. cybotes) will exhibit more variation in perch use and locomotor behavior, than the two macrohabitat specialist species (A. longitibialis and A. marcanoi). Although a range of perch diameters might be available in each habitat, the variation of perches available in the specialist habitats may be reduced, especially in xeric habitats.

Anole ecomorphs also differ in the extent of sexual size dimorphism (SSD), with trunk-ground and trunk-crown species exhibiting relatively high male-biased SSD, and the other four ecomorphs exhibiting relatively low SSD (Butler et al. 2000; Cox et al. 2007). This variation in SSD has been attributed to both ecological variation between the sexes and intrasexual selection (Butler et al. 2000; Cox et al. 2007). Here, we use SSD as a proxy for the strength of precopulatory sexual selection, following the empirical evidence that males in general, and particularly in lizards, evolve larger body sizes as the result of competition for mates or other resources (e.g., Andersson 1994; Cox et al. 2003, 2007). We tested for differences in sexually selected morphologies and behaviors, with the following predictions. (2a) Intense male conflict in anoles might escalate to locking jaws (e.g., Greenberg and Noble 1944; Jenssen et al. 2000); therefore, species with high SSD should exhibit relatively 
larger head dimensions, which offer stronger bite forces (e.g., Herrel et al. 1999, 2001). (2b) Male anoles perform displays that include extensions of the dewlap (a colorful throat fan), head-bobs, and push-ups in courtship and aggression (Jenssen 1977). Thus, we predicted that species with high SSD will have larger dewlaps and more frequent dewlap and push-up display behaviors. (2c) Finally, because precopulatory male competition might be associated with an energetic trade-off with postcopulatory sperm competition (Fitzpatrick et al. 2012; Parker et al. 2013; Lüpold et al. 2014; Kahrl et al. 2016), we predicted that species with high SSD will have smaller testes.

\section{Materials and Methods}

\section{Measures of Behavior and Habitat Use}

We examined adult male anoles of the three focal species in the Dominican Republic during the summer breeding season in 2005, 2009, 2010, and 2015. We studied Anolis cybotes at Coralsol Beach Resort in La Ciénaga, Barahona $\left(18^{\circ} 03^{\prime} 42.2^{\prime \prime} \mathrm{N},-71^{\circ} 06^{\prime} 39.9^{\prime \prime} \mathrm{W}\right.$; in all cases, datum = WGS84); A. longitibialis in Manuel Goya $\left(17^{\circ} 50^{\prime} 8.5^{\prime \prime} \mathrm{N},-71^{\circ} 27^{\prime} 0.5^{\prime \prime} \mathrm{W}\right.$ and $17^{\circ} 48^{\prime} 9.216^{\prime \prime} \mathrm{N}$, $\left.-71^{\circ} 26^{\prime} 51.792^{\prime \prime} \mathrm{W}\right)$; and A. marcanoi near El Matadero $\left(18^{\circ} 23^{\prime} 10.0^{\prime \prime} \mathrm{N}, \quad-70^{\circ} 26^{\prime} 31.4^{\prime \prime} \mathrm{W} ; \quad 18^{\circ} 24^{\prime} 9.936^{\prime \prime} \mathrm{N}\right.$, $-70^{\circ} 25^{\prime} 12.792^{\prime \prime} \mathrm{W}$; and $\left.18^{\circ} 19^{\prime} 30.18^{\prime \prime} \mathrm{N},-70^{\circ} 17^{\prime} 20.508^{\prime \prime} \mathrm{W}\right)$. We performed behavioral observations and morphological measurements in 2015, and recorded habitat use in each of the 4 yr of study.

We conducted focal observations on adult males of each species for 12-120 min/individual (A. cybotes, $n=43,20.6$ h observation; A. longitibialis, $n=31,33.5$ h observation; A. marcanoi, $n=4,6.5 \mathrm{~h}$ observation), as follows. We located undisturbed lizards by walking slowly through the habitat, and then observed the behavior of the focal lizard using binoculars, from a minimum distance of $5 \mathrm{~m}$. During behavioral data collection, we recorded all display behaviors (focusing on dewlap extension and head-bob and pushup displays), locomotor movements (with each movement categorized as a run, crawl, or jump), and copulations. To prevent repeated observations of the same male, we only observed lizards on perches separated by a minimum of 10 $\mathrm{m}$, and we systematically conducted observations in different areas of the locality each day. All observations were performed between $0930 \mathrm{~h}$ and $1730 \mathrm{~h}$, and never in inclement weather (i.e., rain). For each individual, we calculated rates of each display behavior (dewlap extensions, combined head-bobs and push-ups) per min, the total rate of locomotor movements per minute, and the average duration of each dewlap extension in seconds. We also determined the proportion of movements of each locomotor type (runs, crawls, and jumps) and the proportion of fast (runs or jumps) and slow (crawl) movements for each individual.

To obtain measures of habitat use, we noted the type of substrate on which each individual perched during behavioral observations. Perch diameter was collected for lizards that were seen before they were disturbed, and never for lizards that were first seen moving. Additionally, we recorded the orientation of the lizard on the perch as quasi-horizontal $\left(0-30^{\circ}\right)$ or quasi-vertical $\left(31-90^{\circ}\right)$.

\section{Morphological Measurements}

To collect morphological measurements, we captured 20 male and 20 female $A$. cybotes, 17 male and 20 female $A$. longitibialis, and 12 male and 11 female A. marcanoi, by hand or noose (these males were not always the same males on which behavioral observations were performed and perch data were collected). We measured the snout-vent length (SVL) of each lizard to the nearest mm using a plastic ruler. We calculated the average male and female SVL for each species, which was used to calculate the SSD of each species as

$$
\mathrm{SSD}=\frac{\text { Male SVL }}{\text { Female SVL }}-1
$$

following Lovich and Gibbons (1992). If males are larger than females, then by convention this measure of SSD is positive.

We measured a series of additional morphological traits in the adult males. Mass was measured using a Pesola spring scale (to the nearest $0.1 \mathrm{~g}$ ), and external head and limb dimensions were each measured using digital calipers (to the nearest $0.1 \mathrm{~mm}$; Mitutoyo, Japan). Head length was measured as the distance from the parietal eye to the tip of the snout, head width was measured at the widest part of the skull (the anterior base of the cranium), and head depth was measured at the deepest part of the skull (immediately behind the eyes).We measured the femur length as the distance between the body wall and the most distal point of the knee; tibia length as the distance between the knee and the most distal point of the foot; and fourth toe length as the distance between the tip of the longest toe (Metatarsal IV) not including the claw, and the point of insertion of the toe at the footpad. Three characteristics of the subdigital toepad on the fourth toe were also measured: number of lamellae on the toepad, pad length, and pad width. These traits were measured using digital flatbed scans with a resolution of 2400-3200 dots per inch, and were analyzed with the software Image (NIH, USA). All foot measurements were taken twice, and we used the mean of these measures in subsequent analyses (modified after Zani 2000). We measured the hindlimb, fourth toe, and toepad on the right side of the lizard unless it was injured, in which case we measured the left side.

To measure dewlap size, we held the lizard's head parallel to a background of white graph paper and photographed the dewlap, fully extended using forceps, twice for each animal. We measured the area of both photographs of each dewlap using ImageJ, and then used the larger of the two measures in subsequent analyses.

These animals were also used in a series of other physiological studies, so a subset of lizards on which morphological measurements were made were transported to Trinity University and euthanized by rapid decapitation. Immediately following euthanasia, we opened the body cavity and measured the length and width of the right testis, before the testis was removed from the specimen. These measures were used to calculate testis volume using the formula for the volume of an ellipsoid $\left(4 / 3 \pi a^{2} b\right)$, where $a$ is the radius of the width of the testis and $b$ is the radius of its length. We converted this measure of testis volume to a measure of mass using the density of testis tissue $\left(1 \mathrm{~mm}^{3} / \mathrm{mg}\right)$ 
TABLE 1.- Results from separate analyses of variance testing for differences in $\log _{10}$-transformed body size (SVL), Head Size PC, and body size corrected morphology (residuals of morphological traits regressed against SVL) among Anolis cybotes, A. longitibialis, and A. marcanoi. Statistically significant comparisons are indicated with an asterisk $\left.{ }^{*}\right)$.

\begin{tabular}{lrc}
\hline Trait & $F_{2,39}$ & $P$ \\
\hline Log ${ }_{10}$ SVL & 12.24 & $<0.001^{*}$ \\
Residual mass & 5.33 & $0.01^{*}$ \\
Residual head length & 2.86 & 0.07 \\
Residual head width & 0.35 & 0.74 \\
Residual head depth & 0.33 & 0.72 \\
Head size PC & 8.15 & $0.001^{*}$ \\
Residual femur length & 16.16 & $<0.001^{*}$ \\
Residual tibia length & 4.66 & $0.02^{*}$ \\
Residual fourth toe & 9.47 & $<0.001^{*}$ \\
Residual toepad length & 2.12 & 0.16 \\
Residual toepad width & 3.30 & 0.07 \\
Number of lamellae & 5.56 & $0.02^{*}$ \\
Residual dewlap size & 11.89 & $0.001^{*}$ \\
\hline
\end{tabular}

reported by Licht and Pearson (1969). We then calculated gonadosomatic index (GSI, the ratio of testis mass to body mass) for each individual.

\section{Statistical Analysis}

We conducted all statistical analyses in JMP (v9.0, 2010; SAS Institute Inc., USA). All morphological traits were $\log _{10^{-}}$ transformed for our analyses. Head measurements are highly correlated, so we used Principal Component Analysis (PCA) to reduce dimensionality of $\log _{10}$ head length, $\log _{10}$ head width, and $\log _{10}$ head depth. This returned one significant $\mathrm{PC}\left(\chi^{2}=135.34 \mathrm{df}=5, P<0.001\right)$ that explained $92.6 \%$ of the variance and had positive loadings of head length (0.95), depth (0.96), and width (0.97). We interpreted this PC as an overall measure of head size, and included this as Head Size $\mathrm{PC}$ in subsequent analyses.

To test for differences among species in body shape, we used body size-corrected residuals from the regression of the $\log _{10}$-transformed trait on $\log _{10}$ SVL, which included all males of all species. We then used a series of analyses of variance (ANOVA) to test for differences among the three species in $\log _{10}$ SVL, Head Size PC, GSI, number of lamellae on the fourth toepad, and the residuals of mass, head length, head width, head depth, femur length, tibia length, fourth toe length, fourth toepad length and width, and dewlap size. We used Tukey's Honest Significant Difference post hoc tests for all pair-wise comparisons following significant ANOVA results.

We used a series of ANOVAs to test for differences among species in the following dependent variables: rates of behavioral traits (dewlap extension, head-bobs and push-ups, total movements), proportion of type of locomotor movements (runs, crawls, or jumps) as well as fast (runs and jumps) and slow (crawls) movements, and the average duration of dewlap extension among the species. Copulation was rarely observed during these observations (in total, we saw only one pair of A. cybotes copulate during this study), and thus this behavior could not be statistically analyzed. We used a series of Brown-Forsythe tests to assess the equality of variance in behavioral traits among the species. We also tested for differences in substrate use and substrate orientation (quasi-horizontal or quasi-vertical) between species using $\chi^{2}$ tests. We compared differences in perch diameter between A. cybotes and A. marcanoi using ANOVA. Our data on perch diameter for A. longitibialis were very limited; therefore, we removed A. longitibialis from the analysis of perch diameter.

\section{RESULTS}

Morphological analysis showed that the three cybotoid species differed in body size and limb dimensions (Table 1; Fig. 2; Table S1 in the Supplemental Materials available online). Anolis cybotes and A. longitibialis did not differ in SVL, but A. cybotes had the largest relative mass, whereas A. marcanoi was the smallest species in both measures of overall size. We also found that A. longitibialis had longer hindlimbs and shorter fourth toes with fewer lamellae than A. cybotes and A. marcanoi, and A. cybotes had shorter hindlimbs, longer toes, and more lamellae than the other species (Table 1; Fig. 2).

In addition, we found that the species differed in locomotor behavior and perch type (Fig. 3; Table S2 in the Supplemental Materials available online). Anolis cybotes moved more frequently than $A$. longitibialis $\left(F_{2,49}=6.23, P=0.003\right.$; Fig. 3 ), and had a greater variation in the frequency of their movements $\left(F_{2,75}=6.83, P=0.001\right)$. However, the proportion of each type of movement (runs, crawls, and jumps) did not differ among the three species (all $P>0.17$; Fig. 3), nor did the proportion of fast movements (runs and jumps; $F_{2,69}=0.10, P=0.25$ ), or slow movements (crawls; $\left.F_{2,69}=2.38, P=0.10\right)$. The variance of each of these types of movements was similar among all three species (all $P>0.18$ ).

Perch use differed among the species $\left(\chi^{2}=122.9\right.$, $\mathrm{df}=10$, $P<0.001)$; A. longitibialis was most often found on rocks, while A. marcanoi was most often found on fence posts and tree trunks. Anolis cybotes occupied the widest range of habitats, but was predominantly found on tree trunks and branches (Fig. 3), and was found on vertical branches more often than A. marcanoi and A. longitibialis $\left(\chi^{2}=13.05, \mathrm{df}=\right.$ 2, $P=0.001)$. We found no difference in perch diameter between $A$. cybotes and $A$. marcanoi $\left(F_{1,26}=3.06, P=0.09\right)$.

The three species also differed in the extent of SSD, with A. longitibialis (SSD $=0.352$ ) exhibiting the most malebiased dimorphism, followed by $A$. cybotes (SSD $=0.169$ ), and A. marcanoi (SSD $=0.085$ ). Consistent with our predictions, the species with smallest SSD (A. marcanoi) had the smallest heads (Head Size PC; Fig. 4A), but it exhibited the largest relative dewlaps (Table 1; Fig. 4D). Despite differences in the Head Size PC, the three species were similar in head length, width, and depth (Table 1). Furthermore, our prediction that other morphological and behavioral traits associated with precopulatory sexual selection would show a directional pattern with the extent of SSD was not supported. Anolis cybotes, the species with intermediate SSD, performed a higher rate of dewlap extensions (Fig. 4E; $F_{2,77}=12.20, P<0.001$ ) and headbobs/push-ups (Fig. $4 \mathrm{C} ; F_{2,77}=13.31, P<0.001$ ) than $A$. longitibialis. The average duration of dewlap extension was similar between the two species (Fig. $4 \mathrm{~F} ; F_{2,59}=2.18, P=$ 0.122 ). Testis morphology differed among the three species, with the least dimorphic species (A. marcanoi) having a larger GSI than the two more dimorphic species (Fig. 4B; $\left.F_{2,49}=6.23, P=0.003\right)$. 

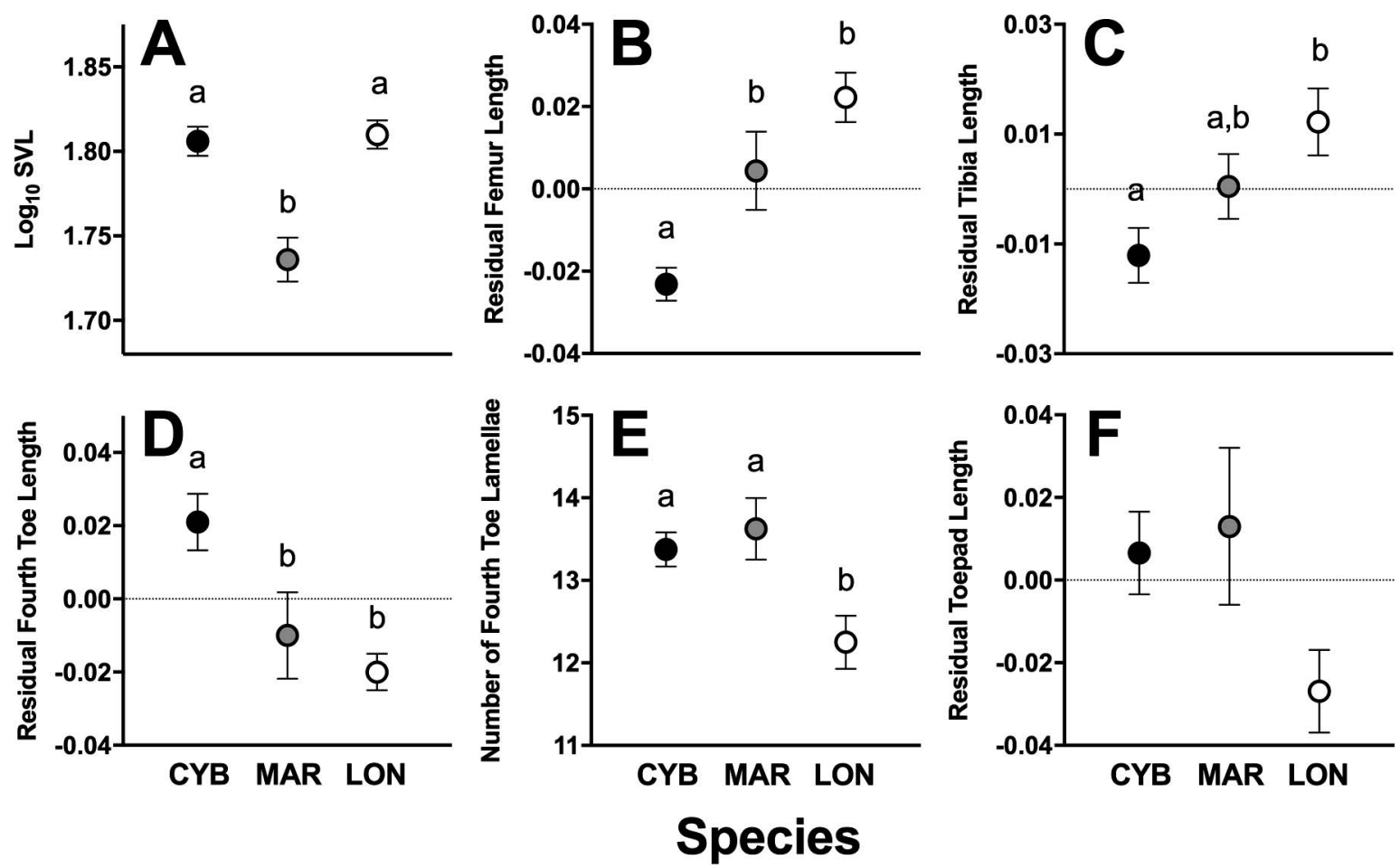

FIG. 2.-Means $\pm 1 \mathrm{SE}$ of $\log _{10}$ snout-vent length (SVL; A), residual femur length (B), residual tibia length (C), residual fourth toe length (D), number of lamellae on the fourth hindlimb toe (E), and residual fourth toepad length (F) for Anolis cybotes (CYB; $n=17)$, A. marcanoi (MAR; $n=7)$ and A. longitibialis (LON; $n=17$ ). Superscripts denote differences between species $(P<0.05)$.

\section{Discussion}

Caribbean anoles are a classic example of adaptive radiation via niche partitioning, given that ecomorphs have evolved to occupy a wide range of microhabitats (Williams 1983; Losos 2009). Yet even within the ecomorph groups, several clades have undergone further diversification within their particular microhabitat on a given island (Burnell and Hedges 1990; Glor et al. 2003, 2004; Knouft et al. 2006; Wollenberg et al. 2013). The cybotoid anoles provide a model for studying local adaptation and speciation within a clade because this group occupies a wide range of habitats on Hispaniola, and exhibits morphological differences that could be attributed to this ecological variation. We have demonstrated differences in the morphology, ecology, and behavior of three species of closely related cybotoid anoles. Consistent with our predictions, the differences in substrate use, morphology, and behavior within this ecomorph mirror some patterns of diversification among other anole ecomorphs, and among other species of lizards. This indicates that each cybotoid species has experienced local adaptation to the variable habitats in the Dominican Republic. For example, among anole ecomorphs, species that use broader perches tend to have longer limbs (Losos and Sinervo 1989;

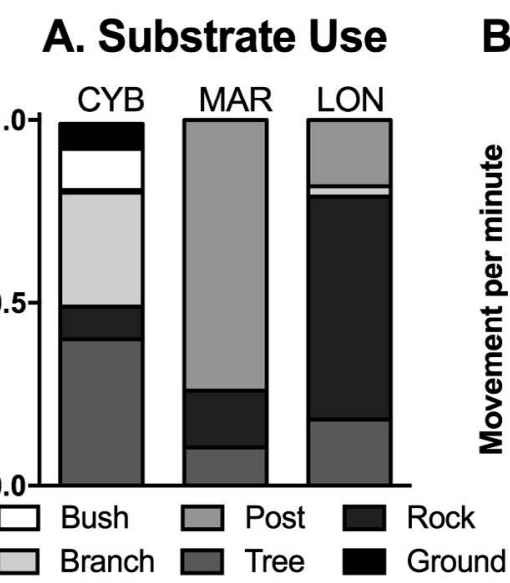

\section{B. Movement Rate}

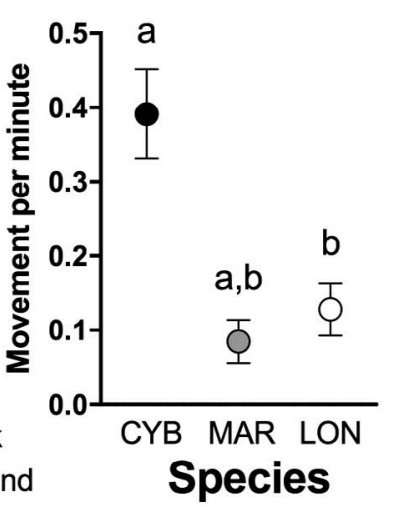

C. Movement Type

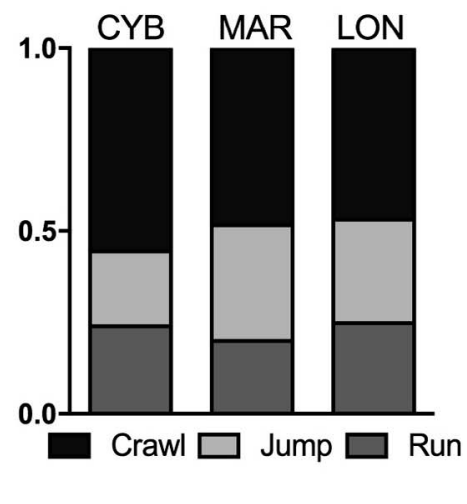

Fig. 3.-Comparisons of ecology (substrate use, A), and behavior (mean $\pm 1 \mathrm{SE}$ of the movement rate, B, and movement type, C) for Anolis cybotes (CYB), A. marcanoi (MAR), and A. longitibialis (LON). Substrate use (A) is graphed as a proportion of total observation. Movement rate (B) was calculated as the total number of movements (run, crawl, and jump) per minute. Movement type (C) is expressed as a proportion of the total movements observed for each species. 

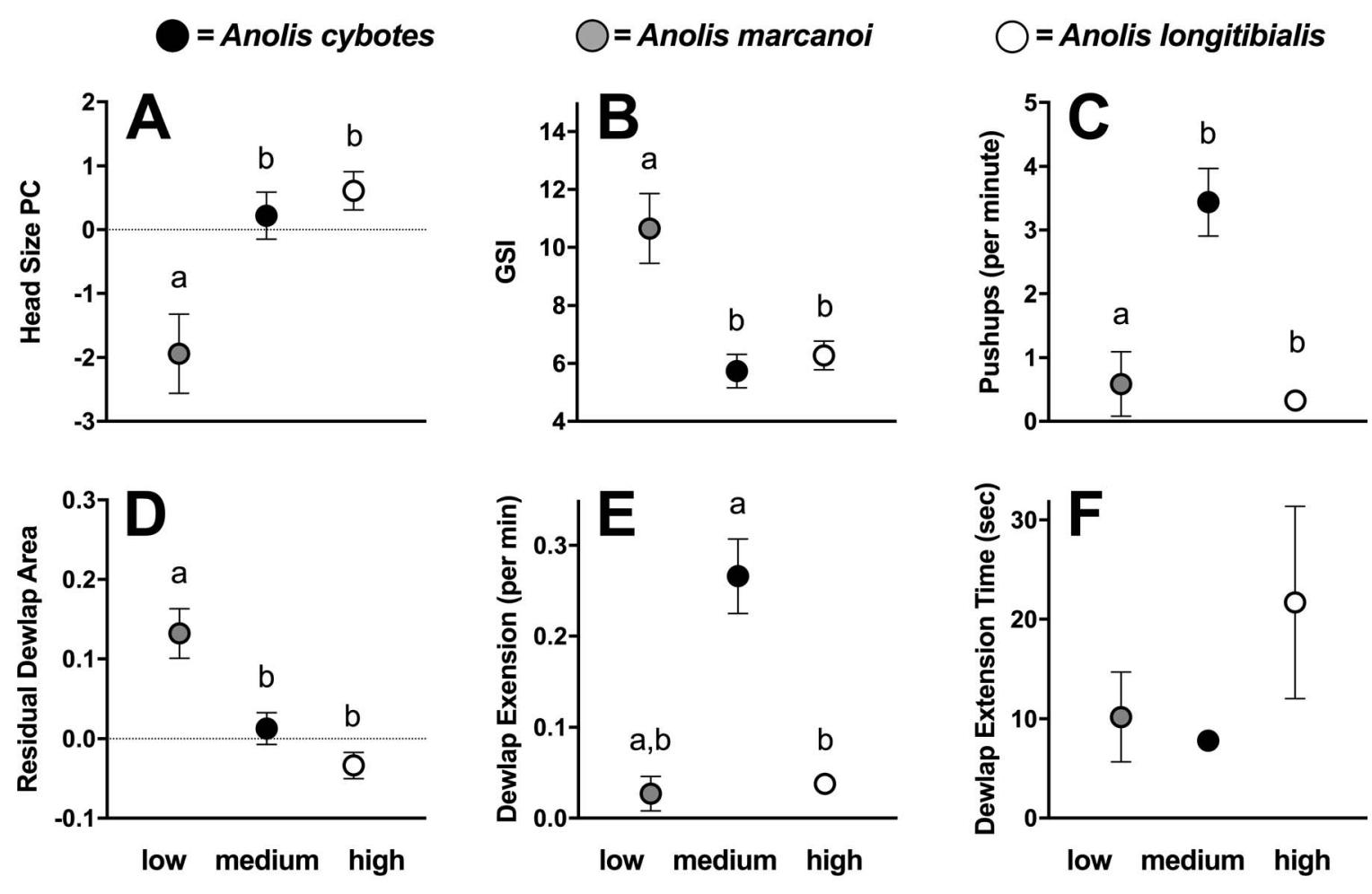

\section{Sexual size dimorphism}

FIG. 4.-Comparisons of sexual size dimorphism (SSD) and other sexually selected traits in cybotoid anoles. Means $\pm 1 \mathrm{SE}$ of the principal component representing of lizard head size (Head Size PC; A), gonadosomatic index (GSI; B), push-ups per minute (C), residual dewlap area (D), dewlap extensions per minute (E), and dewlap extension time (F) for Anolis cybotes, A. marcanoi, and A. longitibialis. These data are presented in order of increasing extent of sexual size dimorphism in each species: A. marcanoi ( $\mathrm{SSD}=0.085)$, A. cybotes $(\mathrm{SSD}=0.169)$, and A. longitibialis $(\mathrm{SSD}=0.352)$.

Losos 1990). Our data also indicate that species with low male-biased dimorphism tend to have smaller heads and larger testes, consistent with theory on sexually selected traits in this group (Kahrl et al. 2016). We found no relationship, however, between SSD and social display behaviors. Although we found differences in these traits among species, we could not directly test for associations between morphology, ecology, and behavior because we only examined these traits in three species of anoles. However, these data provide one of the first comparisons of behavior and sexually selected traits in this group.

\section{Morphology and Substrate Use}

Cybotoid anoles are a morphologically diverse group that inhabit a range of perch substrates and macrohabitats in the Dominican Republic (Glor et al. 2003). Accordingly, we hypothesized that variation in microhabitat or substrate use might have led to predicable changes in morphology and behavior, similar to the patterns of ecomorphological divergence across Caribbean anoles (Losos and Sinervo 1989; Losos 1990). For the three species examined here, we found that the species using the narrowest perches also has shorter hindlimbs, and longer fourth toes with more lamellae on the toepad (Anolis cybotes; Figs. 2, 3). This result is consistent with patterns of adaption among species across ecomorphs, where species that live on smaller perches tend to have shorter limbs with more lamellae, traits thought to aid in clinging ability while running on small perches (Cartmill 1985; Pounds 1988; Losos 1990). Our results also corroborate previous research showing deterministic evolution in morphology of $A$. cybotes, which partially mirrored diversification in previous stages of this adaptive radiation (Wollenberg et al. 2013). Together, these traits indicate that this species has likely adapted to climbing and running on relatively narrow perches (Irschick et al. 1996; Zani 2000).

We also found that the morphology associated with living on rocks in A. longitibialis mimics the patterns of morphology seen in other species of lizards. In particular, the longer limbs of A. longitibialis might be an adaptation to its habitat that enable this species to run faster and jump farther on broad, rocky surfaces (Losos 1990; Irschick and Losos 1999). Similar morphological features occur in other saxicolous anoles, including $A$. eugenegrahami and $A$. aquaticus, who have elongated limbs and flattened bodies (Leal et al. 2002; Muñoz et al. 2015). This morphological adaptation is not limited to anoles, but is common among other groups of lizards. In fact, the evolution of long limbs, toes, and flattened bodies has been repeated in five other lineages of rock-dwelling lizards (Revell et al. 2007; Goodman et al. 2008), and is linked with improved performance in jumping, sprinting, and climbing on rocky habitats (Goodman et al. 2008). This indicates that the ecomorphological adaptations seen in anoles can serve as a general model for how other species of lizards might adapt to specialized habitats.

Species might exhibit population-level variation-especially those that, like the cybotoid anoles, exist across heterogeneous landscapes. Therefore, it is important to 
recognize that there are limitations in using data from one or a few populations to represent a species. The data presented here are a snapshot of the true diversity in behavior, morphology, and substrate use in each species. In particular, we examined a lowland population of A. cybotes in this study, yet this species occurs in montane areas as well. Parallel to the ecomorphological associations among the three species reported in this study, A. cybotes exhibits similar ecomorphological associations in limb dimensions and microhabitat along the altitudinal clines of Hispaniola (Wollenberg et al. 2013; Muñoz et al. 2014). This intraspecific variation further supports the idea that local ecomorphological adaptation in cybotoids is widespread, both within and among each species.

\section{Behavior and Substrate Use}

Contrary to our hypothesis, we found no difference in the proportion of fast or slow movements between species of anoles. We did find, however, that the long-limbed saxicolous species (A. longitibialis) tended to move less frequently than the short-limbed tree-dwelling species (A. cybotes). This relationship between microhabitat use and movement rate again mimics relationships observed among older stages of the anole radiation, where species that live on tree trunks or branches tend to have greater movement rates than those that live near or on the ground (Johnson et al. 2008). This variation in movement rate might be caused by differences in foraging behavior among species, associated with variation in visibility from the lizard's perch (Johnson et al. 2008). In particular, microhabitats with a greater density of twigs and branches tend to obscure visibility, and lizards might move more frequently to survey the areas around them for prey or conspecifics (Moermond 1979).

We also tested the hypothesis that generalist species, which use more diverse substrates, exhibit greater variation in their locomotor behavior. Anolis cybotes used the widest variety of substrates, while both A. marcanoi and $A$. longitibialis were observed on fewer substrate types, and on a single substrate type $>60 \%$ of the time (Fig. 3A). This difference in perch use might be a function of speciesspecific preferences for particular perches, perch availability, or an interaction of the two factors (Johnson et al. 2006; Herrmann 2017). Consistent with our hypothesis, we also found that individual A. cybotes had greater variation in their overall movement rate than members of the other two species. Because A. cybotes occupies more diverse perch types, there might be greater variation in visibility and therefore, high variation in movement rates in this species (Moermond 1979). We note that our behavioral observations of A. marcanoi were limited, however, and our species-level quantification of their behavior may be estimated with some error.

\section{Sexually Selected Traits}

We measured several traits associated with pre- and postcopulatory selection in each of these three species to examine patterns between SSD, morphology, and social behavior. Although we could not statistically test this relationship among species, we observed patterns consistent with hypotheses about how precopulatory selection might influence trait evolution among species. These species vary in the extent of male-biased sexual size dimorphism (Fig. 4), which can result from precopulatory selection on male body size (Butler et al. 2000; Cox et al. 2003, 2007). We predicted that species with high male-biased SSD would also have larger heads, and deeper and wider heads in particular because of the use of the head for biting during male-male combat (Lailvaux et al. 2004; Lailvaux and Irschick 2007). We found that the species with medium and high SSD (A. longitibialis and A. cybotes) had larger heads (Head Size PC) than the species with low SSD, A. marcanoi (Fig. 4A). Whereas lizard bite force or head size can predict the outcomes of male-male combat (e.g., Hews 1990; Pratt et al. 1992; López et al. 2002; Gvozdík and Van Damme 2003; Husak et al. 2006), little comparative work in squamates has tested the hypothesis that species with high male-biased SSD also have positive allometry for head size (Carothers 1984). Our study suggests a positive association between SSD and head size, but many more species should be sampled to test this hypothesis.

We also predicted that species with high male-biased SSD would exhibit larger dewlaps and higher display rates, but we found that the species with the highest male-biased SSD had the smallest dewlap area (Fig. 4). We also found no similarity between SSD and display rate in these species (Fig. 4). A variety of hypotheses have been proposed to explain variation in dewlap size and patterning among species of anoles (Williams and Rand 1977; Losos and Chu 1998; Leal and Fleishman 2004; Nicholson et al. 2007). Many tests of these hypotheses have found weak or no support for differences among ecomorph groups or for variation attributable to species recognition (Nicholson et al. 2007). Among islands, anole species that co-occur with other species of anoles did not differ in their dewlaps when other cues for species recognition were present (i.e., when there were strong differences in other phenotypic traits). In populations where other cues were lacking, however, anoles tended to have more variable dewlap colors (Williams and Rand 1977). Among the three populations that we sampled, A. marcanoi had reddish-pink dewlaps, whereas both A. cybotes and A. longitibialis had pale yellow or white dewlaps. Although our data cannot test this hypothesis, these observed differences in dewlap size and color might aid in species-recognition, especially given the physical similarities between these species. Whereas it was not a focus of our study, dewlap size is also weakly associated with habitat illumination, which might contribute to the evolution of the dewlap (Losos and Chu 1998; Leal and Fleishman 2004).

We observed that species with higher male-biased SSD had smaller testes (Fig. 4B). This pattern was consistent with our predictions of a trade-off between pre- and postcopulatory selection, and mirrors a trade-off that exists both among other species of anoles and across all squamates (Lailvaux et al. 2004; Lailvaux and Irschick 2007; Kahrl et al. 2016). This indicates that the patterns of diversification in morphology attributable to sexual selection that occur among species are also occurring within ecomorph groups.

Our results might inform patterns of divergence among other sympatric or allopatric anole species that exhibit niche partitioning or local adaptation, respectively, within the same ecomorph (Glor et al. 2003, 2004; Knouft et al. 2006), similar to the patterns observed among ecomorphs on each island (Williams 1983; Losos 1990; Losos et al. 1998). In particular, the cybotoid group of anoles show differences in morphology 
that are independent of their phylogenetic relationships (Glor et al. 2003), which can be attributed to a combination of microhabitat and genetic differentiation between these species (Wollenberg et al. 2013). We found that closely related species-A. cybotes, A. longitibialis, and A. marcanoi-exhibited striking differences in their morphology, ecology, and behavior that might be caused by local adaptation to varying microhabitats and differences in the strength of sexual selection among species, which might represent a yet underexplored dimension of local adaptation.

Acknowledgments.-We thank F. Deckard, M. Jaramillo, M. Webber, A. Zeb, M. Landestoy, and C. Marte for their assistance in field data collection during this study, and L. Selznick and J. Stercula for laboratory support. We also thank the people of Manuel Goya and the staff of Coralsol Beach Resort for their hospitality and logistical support. This study was conducted under permission from the Ministerio de Medio Ambiente y Recursos Naturales of the Dominican Republic, and Trinity University's Animal Research Committee (protocol \#NSF050213_MAJ3 and \#042811MJ1), and was funded by the National Science Foundation (NSF IOS 1257021 to MAJ and NSF HBCU-UP 1435186 to KWV), the E.E. Williams Research Grant from the Herpetologist's League (to AFK), and a Doctora Dissertation Improvement Grant from the National Science Foundation (NSF DEB 1501680 to RMC and AFK).

\section{Supplemental Material}

Supplemental material associated with this article can be found online at https://doi.org/10.1655/Herpetologica-D-1700040.S1; https://doi.org/10.1655/Herpetologica-D-1700040.S2.

\section{Literature Cited}

Andersson, M. 1994. Sexual Selection. Princeton University Press, USA. Burnell, K.L., and S.B. Hedges. 1990. Relationships of West Indian Anolis (Sauria: Iguanidae): An approach using slow-evolving protein loci. Caribbean Journal of Science 26:7-30.

Butler, M.A., T.W. Schoener, and J.B. Losos. 2000. The relationship between sexual size dimorphism and habitat use in Greater Antillean Anolis lizards. Evolution 54:259-272.

Carothers, J.H. 1984. Sexual selection and sexual dimorphism in some herbivorous lizards. American Naturalist 124:244-254.

Cartmill, M. 1985. Climbing. Pp. 73-88 in Functional Vertebrate Morphology (M. Hildebrand, D.M. Bramble, K.F. Liem, and D.B. Wake, eds.). Belknap, USA.

Cox, R.M., S.L. Skelley, and H.B. John-Alder. 2003. A comparative test of adaptive hypotheses for sexual size dimorphism in lizards. Evolution $57: 1653-1669$

Cox, R.M., M.A. Butler, and H.B. John-Alder. 2007. The evolution of sexual size dimorphism in reptiles. Pp. 38-49 in Sex, Size and Gender Roles: Evolutionary Studies of Sexual Size Dimorphism (D.J. Fairbairn, W.U. Blankenhorn, and T. Székely, eds.). Oxford University Press, UK.

Danley, P.D., and T.D. Kocher. 2001. Speciation in rapidly diverging systems: Lessons from Lake Malawi. Molecular Ecology 10:1075-1086.

Esquerré, D., and J.S. Keogh. 2016. Parallel selective pressures drive convergent diversification of phenotypes in pythons and boas. Ecology Letters 19:800-809.

Fitzpatrick, J.L., M. Almbro, A. Gonzalez-Voyer, N. Kolm, and L.W Simmons. 2012. Male contest competition and the coevolution of weaponry and testes in pinnipeds. Evolution 66:3595-3604.

Gifford, M.E., Y.M. Ramos, R. Powell, and J.S. Parmerlee, Jr. 2003. Natura history of a saxicolous anole, Anolis longitibialis from Hispaniola. Herpetological Natural History 9:15-20

Glor, R.E., J.J. Kolbe, R. Powell, A. Larson, and J.B. Losos. 2003 Phylogenetic analysis of ecological and morphological diversification in Hispaniolan trunk-ground anoles (Anolis cybotes group). Evolution $57: 2383-2397$

Glor, R.E., M.E. Gifford, A. Larson, J.B. Losos, L.R. Schettino, A.R.C. Lara, and T.R. Jackman. 2004. Partial island submergence and speciation in an adaptive radiation: A multilocus analysis of the Cuban green anoles. Proceeding of the Royal Society of London B: Biological Sciences 271:2257-2265.
Glossip, D., and J.B. Losos. 1997. Ecological correlates of number of subdigital lamellae in anoles. Herpetologica 53:192-199.

Goodman, B.A., D.B. Miles, and L. Schwarzkopf. 2008. Life on the rocks: Habitat use drives morphological and performance evolution in lizards. Ecology 89:3462-3471.

Greenberg, B., and G.K. Noble. 1944. Social behavior of the American chameleon (Anolis carolinensis Voigt). Physiological Zoology 17:392-439.

Gvozdík, L., and R. Van Damme. 2003. Evolutionary maintenance of sexual dimorphism in head size in the lizard Zootoca vivipara: A test of two hypotheses. Journal of Zoology 259:7-13.

Hedges, S.B. 1989. Evolution and biogeography of West Indian frogs of the genus Eleutherodactylus: Slow-evolving loci and the major groups. Pp. 305-370 in Biogeography of the West Indies: Past, Present, and Future (C.A. Woods, ed.). Sandhill Crane Press, USA.

Herrel, A., L. Spithoven, R. Van Damme, and F. De Vree. 1999. Sexual dimorphism of head size in Gallotia galloti: Testing the niche divergence hypothesis by functional analyses. Functional Ecology 13:289-297.

Herrel, A., E.D. Grauw, and J.A. Lemos-Espinal. 2001. Head shape and bite performance in xenosaurid lizards. Journal of Experimental Zoology 290:101-107.

Herrmann, N.C. 2017. Substrate availability and selectivity contribute to microhabitat specialization in two Central American semiaquatic anoles. Breviora 555:1-13.

Hertz, P.E., Y. Arima, A. Harrison, R.B. Huey, J.B. Losos, and R.E. Glor. 2013. Asynchronous evolution of physiology and morphology in Anolis lizards. Evolution 67:2101-2113.

Hews, D.K. 1990. Examining hypotheses generated by field measures of sexual selection on male lizards, Uta palmeri. Evolution 44:1956-1966.

Husak, J.F., A.K. Lappin, S.F. Fox, and J.A. Lemos-Espinal. 2006. Bite-force performance predicts dominance in male venerable collared lizards (Crotaphytus antiquus). Copeia 2006:301-306.

Irschick, D.J., and J.B. Losos. 1998. A comparative analysis of the ecological significance of maximal locomotor performance in Caribbean Anolis lizards. Evolution 52:219-226.

Irschick, D.J., and J.B. Losos. 1999. Do lizards avoid habitats in which performance is submaximal? The relationship between sprinting capabilities and structural habitat use in Caribbean anoles. American Naturalist 154:293-305.

Irschick, D.J., C.C. Austin, K. Petren, R.N. Fisher, J.B. Losos, and O. Ellers. 1996. A comparative analysis of clinging ability among pad-bearing lizards. Biological Journal of the Linnean Society 59:21-35.

Jenssen, T.A. 1977. Evolution of anoline lizard display behavior. American Zoologist 17:203-215.

Jenssen, T.A., K.S. Orrell, and M.B. Lovern. 2000. Sexual dimorphisms in aggressive signal structure and use by a polygynous lizard, Anolis carolinensis. Copeia 2000:140-149.

Johnson, M.A., R. Kirby, S. Wang, and J.B. Losos. 2006. What drives habitat use by Anolis lizards: Habitat availability or selectivity? Canadian Journal of Zoology 84:877-886.

Johnson, M.A., M. Leal, L.R. Schettino, A.C. Lara, L.J. Revell, and J.B. Losos. 2008. A phylogenetic perspective on foraging mode evolution and habitat use in West Indian Anolis lizards. Animal Behaviour 75:555-563.

Kahrl, A.F., C.L. Cox, and R.M. Cox. 2016. Correlated evolution between targets of pre- and postcopulatory sexual selection across squamate reptiles. Ecology and Evolution 6:6452-6459.

Kamath, A., and J.B. Losos. 2017. Does ecological specialization transcend scale? Habitat partitioning among individuals and species of Anolis lizards. Evolution 71:541-549.

Knouft, J.H., J.B. Losos, R.E. Glor, and J.J. Kolbe. 2006. Phylogenetic analysis of the evolution of the niche in lizards of the Anolis sagrei group. Ecology 87:S29-S38.

Kolbe, J.J., A.C. Battles, and K.J. Avilés-Rodríguez. 2015. City slickers: Poor performance does not deter Anolis lizards from using artificial substrates in human-modified habitats. Functional Ecology 30:1418-1429.

Lailvaux, S.P., and D.J. Irschick. 2007. The evolution of performance-based male fighting ability in Caribbean Anolis lizards. American Naturalist 170:573-586.

Lailvaux, S.P., A. Herrel, B. VanHooydonck, J.J. Meyers, and D.J. Irschick. 2004. Performance capacity, fighting tactics and the evolution of life-stage male morphs in the green anole lizard (Anolis carolinensis). Proceedings of the Royal Society of London B: Biological Sciences 271:2501-2508.

Leal, M., and L.J. Fleishman. 2004. Differences in visual signal design and detectability between allopatric populations of Anolis lizards. American Naturalist 163:26-39. 
Leal, M., A.K. Knox, and J.B. Losos. 2002. Lack of convergence in aquatic Anolis lizards. Evolution 56:785-791.

Licht, P., and A.K. Pearson. 1969. Effects of adenohypophysectomy on testicular function in the lizard Anolis carolinensis. Biology of Reproduction 1:107-119.

López, P., A. Muñoz, and J. Martín. 2002. Symmetry, male dominance and female mate preferences in the Iberian rock lizard, Lacerta monticola. Behavioral Ecology and Sociobiology 52:342-347.

Losos, J.B. 1990. Ecomorphology, performance capability, and scaling of West Indian Anolis lizards: An evolutionary analysis. Ecological Monographs 60:369-388.

Losos, J.B. 1996. Ecological and evolutionary determinants of the speciesarea relation in Caribbean anoline lizards. Philosophical Transactions of the Roval Society of London B 351:847-854.

Losos, J.B. 2009. Lizards in an Evolutionary Tree: Ecology and Adaptive Radiation of Anoles. University of California Press, USA.

Losos, J.B., and L.R. Chu. 1998. Examination of factors potentially affecting dewlap size in Caribbean anoles. Copeia 1998:430-438.

Losos, J.B., and B. Sinervo. 1989. The effects of morphology and perch diameter on sprint performance of Anolis lizards. Journal of Experimental Biology 145:23-30.

Losos, J.B., T.R. Jackman, A. Larson, K. de Queiroz, and L. RodríguezSchettino. 1998. Contingency and determinism in replicated adaptive radiations of island lizards. Science 279:2115-2118.

Lovich, J.E., and J.W. Gibbons. 1992. A review of techniques for quantifying sexual size dimorphism. Growth, Development and Aging 56:269-281.

Lüpold, S., J.L. Tomkins, L.W. Simmons, and J.L. Fitzpatrick. 2014. Female monopolization mediates the relationship between pre- and postcopulatory sexual traits. Nature Communications 5:3184.

Moermond, T.C. 1979. The influence of habitat structure on Anolis foraging behavior. Behaviour 70:147-167.

Muñoz, M.M., J.E. Wegener, and A.C. Algar. 2014. Untangling intra- and interspecific effects on body size clines reveals divergent processes structuring convergent patterns in Anolis lizards. American Naturalist 184:636-646

Muñoz, M.M., K.E. Crandell, S.C. Campbell-Staton, K. Fenstermacher, H.K. Frank, P. Van Middlesworth, M. Sasa, J.B. Losos, and A. Herrel. 2015. Multiple paths to aquatic specialisation in four species of Central American Anolis lizards. Journal of Natural History 49:1717-1730.

Nicholson, K.E., L.J. Harmon, and J.B. Losos. 2007. Evolution of Anolis lizard dewlap diversity. PLoS One 2:e274. DOI: https://doi.org/ 10.1371/ journal.pone.0000274

Parker, G.A., C.M. Lessells, and L.W. Simmons. 2013. Sperm competition games: A general model for precopulatory male-male competition. Evolution 67:95-109.

Pounds, J.A. 1988. Ecomorphology, locomotion, and microhabitat structure: Patterns in a tropical mainland Anolis community. Ecological Monographs 58:299-320.

Pratt, N.C., A.C. Alberts, K.G. Fulton Medler, and J.A. Phillips. 1992. Behavioral, physiological and morphological components of dominance and mate attraction in male green iguanas. Zoo Biology 11:153-163.

Rand, A.S. 1964. Ecological distribution in anoline lizards of Puerto Rico, Ecology 45:745-752.

Revell, L.J., M.A. Johnson, J.A. Schulte, J.J. Kolbe, and J.B. Losos 2007. A phylogenetic test for adaptive convergence in rock-dwelling lizards. Evolution 61:2898-2912.

Ruibal, R. 1961. Thermal relations of five species of tropical lizards. Evolution 15:98-111.

Schluter, D. 2000. The Ecology of Adaptive Radiation. Oxford University Press, UK.

Williams, E.E. 1972. The origin of faunas. Evolution of lizard congeners in a complex island fauna: A trial analysis. Evolutionary Biology 6:47-89.

Williams, E.E. 1983. Ecomorphs, faunas, island size, and diverse end points in island radiations of Anolis. Pp. 326-370 in Lizard Ecology: Studies of a Model Organism (R.B. Huey, E.R. Pianka and T.W. Schoener, eds.). Harvard University Press, USA.

Williams, E.E., and A.S. Rand. 1977. Species recognition, dewlap function and faunal size. American Zoologist 17:261-270.

Wollenberg, K.C., I.J. Wang, R.E. Glor, and J.B. Losos. 2013. Determinism in the diversification of Hispaniolan trunk-ground anoles (Anolis cybotes species complex). Evolution 67:3175-3190.

Zani, P.A. 2000. The comparative evolution of lizard claw and toe morphology and clinging performance. Journal of Evolutionary Biology 13:316-325.
Accepted on 28 August 2017 Associate Editor: Eric McElroy 